\title{
"Okinawa: A história de um povo insular" de George Kerr
}

\author{
Ana Carolina Warigoda Guedes* \\ Filipe Starke Lee \\ Celso Akihide Shiroma ${ }^{* * *}$ \\ Erica Fernandes Costa ${ }^{* * *}$ \\ Mateus Trigo Gonçalves ${ }^{* * * *}$
}

George Henry Kerr (1911 - 1992) foi um importante pesquisador, acadêmico e diplomata estadunidense, cuja carreira se realizou principalmente no Leste Asiático. Em sua vida, estudou, trabalhou e residiu na Taiwan japonesa durante os anos 1930, e atuou como analista e diplomata por seu país durante a Segunda Guerra Mundial (1939 - 1945), acompanhando de perto os conflitos no Pacífico e suas consequências. Como acadêmico, dedicou-se principalmente aos estudos de Taiwan e Okinawa, além de tangenciar questões japonesas e chinesas pertinentes a esses locais.

Quanto à história de Okinawa, Kerr dedicou-se à pesquisa em arquivos japoneses a partir da década de 1950. Isso resultou na publicação de dois livros, “Okinawa: Reino e

\footnotetext{
* Graduanda em História na Universidade de São Paulo. É membro do Grupo de Estudos Okinawanos da Universidade de São Paulo. E-mail: ana.carolina.guedes@usp.br

${ }^{* *}$ Graduando em História na Universidade de São Paulo. É membro do Grupo de Estudos Okinawanos da Universidade de São Paulo. E-mail: filipe.lee@usp.br

*** Possui graduação em Ciência Política e Teoria das Relações Internacionais pela University Of The Ryukyus (2012). Graduando em Letras - Português pela Universidade de São Paulo. É membro do Grupo de Estudos Okinawanos da Universidade de São Paulo. E-mail: celso.shiroma@usp.br

${ }^{* * \star \star}$ Graduanda em Letras - Japonês na Universidade de São Paulo. É membro do Grupo de Estudos Okinawanos da Universidade de São Paulo. E-mail: erica.costa@usp.br

${ }^{* * \star \star \star}$ Graduando em Direito pela Universidade Presbiteriana Mackenzie e graduando em História pela Universidade de São Paulo. É membro do Grupo de Estudos Okinawanos da Universidade de São Paulo. E-mail: mateus.goncalves@usp.br
} 


\section{resenhas}

\section{Ana Carolina Warigoda Guedes, Filipe Starke Lee, Celso Akihide Shiroma, Erica Fernandes Costa, Mateus Trigo Gonçalves}

Província Antes de 1945" [Okinawa: Kingdom and Province Before 1945] (1953) e "História de Ryukyu" [Ryuukyuu no Rekishi] (1955), este último em japonês. Sua grande síntese, entretanto, viria em 1958, com a obra "Okinawa: A História de um Povo Insular" [Okinawa: The History of an Island People], publicada originalmente pela Tuttle Publishing ${ }^{2}$. Neste livro, o autor constrói uma História okinawana sob diversas perspectivas - social, cultural, econômica e política desde seus primórdios "pré-históricos"³ até os primeiros anos do período pós-Segunda Guerra Mundial. Escrito de maneira acessível e com ricas referências, esse livro é ainda hoje considerado a obra mais consistente em língua inglesa sobre a História de Okinawa 4 .

Em sua primeira parte, obra de Kerr se inicia com a descrição geográfica das ilhas de Okinawa, que são caracterizadas pelo autor como de natureza inóspita, diminutas em tamanho e, em geral, pouco propícias para o assentamento humano (fatores que posteriormente serão centrais para as análises de Kerr). Em relação ao povoamento inicial das ilhas, os primeiros habitantes são descritos como náufragos e refugiados: ou seja, pessoas que não migrariam voluntariamente. Além disso, o autor constantemente compara as várias culturas do período pré-histórico okinawano a regiões vizinhas mais desenvolvidas,

\footnotetext{
${ }^{1}$ Todos os termos traduzidos na resenha são traduções livres nossas.

${ }^{2}$ Reeditada em 2000, edição que utilizamos nesta resenha.

${ }^{3}$ Alguns termos utilizados no corpo da resenha são reproduções daqueles utilizados pelo próprio autor. É o caso do termo "pré-histórico".

${ }^{4}$ Nota sobre os termos utilizados: Okinawa é a principal e maior ilha das ilhas Ryukyu; tal grande arquipélago é localizado ao sul das ilhas centrais do Japão se estendendo de Kyushu até Taiwan, sendo formado por vários arquipélagos menores, entre eles, as Ilhas Okinawa, cuja ilha principal é a homônima Ilha de Okinawa, com capital em Naha. Aqui, usamos Okinawa como referência ao arquipélago menor das "Ilhas Okinawa" (embora a maior parte dos acontecimentos ocorram na ilha principal) bem como de parte de outras ilhas integrantes do grande arquipélago ryukyuano que estiveram em certos momentos política e culturalmente conectadas a ilha de Okinawa; quando necessário, designamos outras ilhas. Já o reino próprio constituído em Okinawa chamava-se Ryukyu, cuja corte se localizava em Shuri, de forma que esses termos só serão utilizados quando designamos o reino independente, não o local físico do arquipélago. Quanto à população, referimo-nos a eles como okinawanos. Vale ressaltar que esses termos são japoneses: em uchinaguchi (língua okinawana ainda viva), o arquipélago é chamado Uchinaa, e os habitantes e seus descendentes, uchinanchu.
} 


\section{resenhas}

“Okinawa: A história de um povo insular" de George Kerr o que reforça a ideia de que quaisquer avanços técnicos ocorridos no arquipélago seriam resultado da introdução de conhecimentos estrangeiros.

O período pré-histórico do arquipélago tem fim com a ascensão de Shunten, o primeiro líder que centraliza seu poder no território de Okinawa, e cuja existência é aceita pela historiografia. Não por acaso, o autor atribui o notório êxito de seu reinado às inovações vindas da Ásia continental e do Japão. Após o fim da dinastia de Shunten, há um período de fragmentação política, em que se fundam três reinos em Okinawa (Nanzan, Chuzan e Hokuzan; respectivamente, reinos do Sul, Centro e Norte). Em seguida, o arquipélago é novamente unificado por Sho Hashi, que, com a fusão dos três reinos sob Chuzan, funda o Reino de Ryukyu e é um de seus soberanos mais celebrados. Seu reinado marca o início de uma época de grande prosperidade: impulsionado por uma extensa rede de comércio que se estendia da China ao mundo árabe, Ryukyu vive sua "era de ouro".

Esse período de apogeu tem fim com dois eventos exteriores a Okinawa. Em primeiro lugar, a chegada de comerciantes europeus coincide com o declínio do comércio ryukyuano. Ainda que não aponte nenhuma relação de causalidade entre ambos os eventos, Kerr nota que, conforme as redes comerciais portuguesas se expandem nos oceanos Índico e Pacífico, as ryukyuanas se retraem em um movimento oposto. Em segundo lugar, a escalada de tensões entre o Japão recém unificado por Toyotomi Hideyoshi e a China situa Ryukyu em uma posição precária. Encurralado entre dois vizinhos muito maiores, o reino acaba se tornando um objeto de disputa entre as ambições japonesas e chinesas; por fim, em 1609, o clã Shimazu, de Satsuma (importante senhorio ${ }^{5}$ do sul do Japão), invade Ryukyu, evento que encerra o período de plena independência de sua história.

As fontes utilizadas pelo autor nessa parte são majoritariamente documentos estrangeiros, como os anais das cortes chinesa ("Anais dos Três Reinos Combatentes"), japonesa, coreana e tailandesa, além de registros de jesuítas viajantes no Leste Asiático.

\footnotetext{
${ }^{5}$ Localidade de maior autonomia e posse da terra, frequentemente aproximado - de maneira eurocêntrica - ao "feudo".
} 


\section{resenhas}

Ana Carolina Warigoda Guedes, Filipe Starke Lee, Celso Akihide Shiroma, Erica Fernandes Costa, Mateus Trigo Gonçalves

Como documento escrito proveniente de Okinawa, Kerr analisa a primeira obra de história okinawana realizada no arquipélago, o Chuzan Seikan. Por fim, também se insere em debates antropológicos quando trata da ocupação das ilhas e formação de sua cultura.

Kerr inicia a segunda parte de sua obra (que aborda os anos de 1573 a 1797) explorando o contexto histórico bastante conturbado no Japão - da ascensão e morte de Toyotomi Hideyoshi até o novo shogunato de Tokugawa leyasu - cujas consequências para o Reino de Ryukyu são a perda de sua soberania para o senhorio de Satsuma. Depois, dedica-se a explicar as consequências da invasão do clã Shimazu e a situação de dupla subordinação de Okinawa perante o Japão e a China - da qual era reino tributário e que também se encontrava em problemas políticos: à época, uma rebelião manchu derrubara a dinastia Ming em Beijing, instaurando a dinastia C'hing. Diante dessa mudança de paradigma, a ilha antes famosa por seu pujante comércio marítimo se viu presa a um acordo extremamente oneroso e prejudicial - era para Satsuma e, depois, para Edo, que a grande maioria dos lucros seriam encaminhados, e não mais para Naha - mergulhando o povo em níveis de pobreza alarmantes e reduzindo o nível de vida das classes nobres.

O autor também aborda a introdução do cultivo de cana-de-açúcar e batata doce, dois produtos que se tornariam importantíssimos para, respectivamente, garantir alguma vantagem comercial diante do mercado japonês e sustentar as camadas populares em períodos de fome, muito recorrentes na ilha. Além disso, o autor faz um extenso registro de costumes, hierarquias e dinâmicas sociais okinawanas, incluindo sua relação frutífera com as artes (especialmente a dança e a música), a particular composição da vila de Kumemura (composta por imigrantes chineses), a leveza de caráter, as tradições religiosas e os eventuais contatos com estrangeiros.

É interessante notar que Kerr se utiliza de variadas fontes para embasar suas descrições históricas. Documentos oficiais, como os tratados firmados entre Ryukyu e Satsuma para a regulamentação do monopólio comercial, foram compilados na íntegra, servindo de 


\section{resenhas}

“Okinawa: A história de um povo insular" de George Kerr sustentáculo para a narrativa do livro. Fontes mais cotidianas também foram listadas e Kerr dá muito peso a cartas de viajantes e representantes de outras nações. Relatórios sobre Okinawa escritos por emissários da corte chinesa, assim como cartas de mercadores e navegantes europeus figuram entre as muitas referências utilizadas pelo autor para embasar sua escrita. Um exemplo recorrente desse tipo de citação é na construção do ideário okinawano para os estrangeiros: "o ideal confuciano era colocado em prática - um governo essencialmente civil, ao mesmo tempo absoluto e patriarcal, sem depender de nenhuma força $\operatorname{armada}^{\prime \prime}$ (CHAMBERLAIN apud KERR, 2000[1958], p. 193).

A terceira parte do livro engloba o período de 1797 a 1878, no qual Kerr descreve Okinawa como "entre dois mundos" ["between two worlds"] (KERR, 2000[1958], p. 235), uma vez que essa se encontrava entre os interesses japoneses (Shogunato Tokugawa) de fechamento de portos, e os interesses das potências ocidentais (EUA, Rússia, França e GrãBretanha) de comercializar com o Japão e quebrar o monopólio holandês. A situação inicial de Okinawa nesta parte era de "dupla subordinação" - entre relações de comércio com a China e o controle do Japão exercido pelo senhorio de Satsuma, ainda que conservando aspectos de autonomia, como a manutenção da monarquia própria de Ryukyu. Entretanto, a entrada dos interesses ocidentais e as mudanças internas nesses impérios asiáticos levariam à mudança drástica nesse cenário.

Nesse período, inicia-se a construção de imagens discrepantes sobre Okinawa: por um lado, viajantes estrangeiros criam o imaginário de um povo cordial e hospitaleiro, essencialmente não beligerante, pintando o arquipélago como porta de entrada (econômica, religiosa e militar) ao Japão; por outro lado, o missionário protestante Bettelheim, após estadia inoportuna e conflituosa ${ }^{7}$, vê os okinawanos como traiçoeiros. Essa visão guiaria a abordagem do Comodoro Perry, enviado a Okinawa para perseguir interesses dos EUA no

\footnotetext{
${ }^{6}$ Original: "Confucius' ideal was carried out - a government purely civil, at once absolute and patriarchal, resting not on any armed force".

${ }^{7}$ Entre as ações do missionário, encontram-se: atracar sem permissão, ocupar um templo sagrado, invadir casas para pregação, desrespeitar leis locais e assediar nativos que trabalhavam aos domingos.
} 


\section{resenhas}

Ana Carolina Warigoda Guedes, Filipe Starke Lee, Celso Akihide Shiroma, Erica

Fernandes Costa, Mateus Trigo Gonçalves

Japão. Sua atuação é descrita por Kerr como coercitiva e autoritária, chegando a designar a relação de poder entre Okinawa e Perry como "o rato e a águia" ["the mouse and eagle"] (KERR, 2000[1958], p. 297).

Afinal, o Comodoro consegue a assinatura do Pacto de Lewchew, que, aliado ao Tratado de Kanagawa ${ }^{8}$, consolida em 1854 os interesses estadunidenses no Japão. Mas há ainda um recrudescimento nas políticas japonesas pelo controle de Okinawa. Kerr chega a insinuar que a incapacidade do shogunato Tokugawa em defender as regiões fronteiriças auxilia na eclosão da Restauração Meiji (1868), que derruba o shogun e retoma o poder efetivo ao Imperador. Dessa forma, o governo centralizado passa a disputar o domínio de Ryukyu de maneira mais incisiva com a China, saindo vitorioso, e então designando o reino como senhorio ["han", em japonês] subordinado a Tóquio. Por fim, a Parte 3 se encerra com a crescente tentativa de anexação de Okinawa como prefeitura ["ken"] ${ }^{9}$ japonesa, o que significaria o fim da própria existência de Ryukyu.

As fontes mais recorrentes nessa parte são: relatos de viajantes estrangeiros em Okinawa, decretos do governo japonês, correspondências entre Perry e os governos dos EUA e de Ryukyu, tratados diplomáticos, acordos comerciais e jornais japoneses. Essas fontes, por vezes, estabelecem visões diferentes sobre um mesmo acontecimento, o que dá maior credibilidade ao estudo.

Na quarta parte, que cobre os anos de 1879 até 1945, Kerr trata do processo de assimilação da cultura japonesa pela população okinawana, a partir da anexação de Ryukyu ao Japão como a prefeitura de Okinawa, até a derrota japonesa na Segunda Guerra Mundial.

\footnotetext{
${ }^{8}$ Respectivamente, os acordos regulavam as trocas comerciais em Naha e reabriam os portos japoneses aos países ocidentais.

${ }^{9}$ Unidade administrativa equivalente a divisões regionais, próximo a "província". Em japonês, é representado pelo sufixo "-ken"; em inglês, é traduzido oficialmente para "prefecture". É o sistema vigente até hoje no Japão.
} 


\section{resenhas}

“Okinawa: A história de um povo insular" de George Kerr

O autor inicia com uma narrativa da anexação, mostrando a reação da corte de Shuri, o tratamento recebido pelo rei de Ryukyu no Japão e as tentativas chinesas de renegociar o domínio do arquipélago, que se encerram com a derrota da China na Guerra Sino-Japonesa em 1895. Essas transformações criam problemas sociais e financeiros no Japão, de forma que Tóquio opta por realizar mudanças na nova prefeitura de Okinawa de forma lenta, mantendo certos privilégios da antiga nobreza e priorizando a educação nacionalista nas classes populares. Essa política educacional tem um papel importante em preparar os okinawanos para reverenciar o imperador japonês e assimilar a língua japonesa, em detrimento de sua cultura própria.

A expansão da monocultura da cana-de-açúcar em Okinawa, vendida de maneira bastante rentável às demais ilhas do Japão, deu-se em detrimento da agricultura de subsistência, tornando a província mais dependente de outras regiões. Um dos eventos mais significativos que ocorreram em Okinawa nesse período foi a reforma agrária de 1903, que eliminou os impostos que a antiga nobreza ainda recebia. Nas últimas décadas do século XIX e primeiras do século XX, o arquipélago apresentou grande aumento populacional, apesar de sofrer com epidemias de cólera e desastres naturais. Assim, a emigração se tornou uma saída promissora para os problemas okinawanos, gerando uma intensa onda emigratória.

Essas políticas de assimilação promovidas pelo governo central japonês em Okinawa tiveram efeito com o crescimento de uma nova juventude okinawana, de forma que, no momento de eclosão da Segunda Guerra Mundial, já havia entre eles um sentimento de lealdade e pertencimento à nação japonesa. Nesse mesmo período, Okinawa volta a ser associada à noção de fronteira estratégica, uma vez que sua localização geográfica constituía um ponto central para o exército japonês; além disso, as recorrentes crises econômicas no arquipélago tornaram sua população suscetível ao recrutamento militar. A partir de 1938, o Japão promove a Lei de Mobilização Geral Nacional ["National General Mobilization Law"] (KERR, 2000[1958], p. 462), a qual cessa as liberdades individuais em Okinawa e permite a 


\section{resenhas}

Ana Carolina Warigoda Guedes, Filipe Starke Lee, Celso Akihide Shiroma, Erica Fernandes Costa, Mateus Trigo Gonçalves

utilização de algumas de suas regiões pelo exército japonês, também mobilizando grande número de jovens okinawanos para o conflito.

Com o avanço da Guerra e o acirramento das disputas, o território okinawano foi vítima de bombardeios (p.e. Naha, em outubro de 1944) e presenciou a Batalha de Okinawa, iniciada em abril de 1945 e marcante da resolução dos jogos de força no Pacífico. Esse conflito foi um ponto de reviravolta nos poderes combatentes, com a saída dos EUA fortalecidos e o Japão enfraquecido. Além disso, seu efeito sobre a vida dos okinawanos foi drástico: em primeiro lugar, foram contabilizadas (apenas na Batalha de Okinawa), mais de 47 mil baixas civis ${ }^{10}$. Em segundo lugar, os exércitos estadunidenses que lá atracaram em abril de 1945 nunca deixaram Okinawa. Com a derrota japonesa na Segunda Guerra Mundial, houve o estabelecimento de bases militares dos EUA em Okinawa no período pós-guerra, e "a ilha se tornou um imenso, negligenciado depósito de lixo militar" (KERR, 2000[1958], p. 5) ${ }^{11}$.

Como embasamento de seu estudo, o autor cita nomes como Ota Chofu, Basil Hall Chamberlain, obras sobre a imigração okinawana na América Latina, diários de viagem, publicações ocidentais e japonesas sobre a batalha de Okinawa, referências culturais (como o artesanato okinawano) e um relatório a respeito do tesouro de Shuri, que teria sobrevivido à guerra.

Tendo em vista a exposição feita até este ponto sobre o autor, a obra, sua estrutura argumentativa e fontes, podemos traçar algumas conclusões quanto ao projeto e posicionamento de George Kerr ao longo de seu livro.

Nesta obra, é notável o projeto do autor de formular uma síntese da história okinawana, desde os primeiros processos de ocupação humana do arquipélago, até o período em que o autor escrevia (anos 1950). Essa síntese histórica leva o autor a recorrer a

\footnotetext{
${ }^{10}$ Dados fornecidos pelo autor (KERR, 2000[1958], p. 472)

${ }^{11}$ Original em inglês: "The island became an immense, neglected military dump"
} 


\section{resenhas}

“Okinawa: A história de um povo insular" de George Kerr

diversas abordagens, de forma que trata alternadamente de temas culturais, sociais, econômicos e políticos, recorrendo a fontes diversas, como já mencionadas. Essa história não é contada, entretanto, sem um movimento interno a ela: em muitos sentidos, Kerr narra a construção de um reino (Ryukyu) e uma cultura propriamente okinawanos, e a gradual perda de sua autonomia para poderes maiores, com o triunfo final da conquista pelo Japão. Nesse sentido, pode-se dizer que o autor tece, prematuramente, uma narrativa de longa duração, sob uma perspectiva da "história dos vencidos" - ou seja, a longa história de um povo que sucumbiu perante potências mais poderosas.

Quanto à representação dos okinawanos na obra, vale ressaltar que, embora Kerr os apresente como reféns de acontecimentos externos, ainda Ihes atribui a defesa de seus interesses próprios, muito embora não possuíssem poder suficiente para prosperarem. Nesse sentido, quanto às relações entre Okinawa e os demais atores, é preferível a metáfora de Spalding (membro da missão de Perry), o qual assim denomina o Pacto de Lewchew: “Pacto da Galinha com o Cavalo no Estábulo: eu não pisarei nos seus pés se você não pisar nos meus."12 (SPALDING, apud KERR, 2000[1958], p. 244), em detrimento de uma representação mais simplista como aquela, já mencionada, do "rato e a águia". Mantém-se, portanto, uma agência dos personagens okinawanos, a qual apenas não triunfa porque possui potência menor em relação aos interesses externos sobre eles.

É possível, ainda, refletir se Kerr assume um posicionamento pró-identidade okinawana, mais simpática aos EUA, em oposição à identidade japonesa que foi então assimilada pela população. Isso é por vezes justificado devido às menções frequentemente negativas ao poderio japonês e seu domínio de Okinawa - tanto por Satsuma, quanto posteriormente pelo governo central de Tóquio. Entretanto, Kerr também tece críticas aos personagens simbólicos do poder ocidental na obra, como a coerção excessiva de Perry e as atitudes inoportunas de Bettelheim, além da constatação dos danos à população nativa e civil durante a Segunda

\footnotetext{
${ }^{12}$ Original em inglês: “Compact of the Chicken with the Horse in the Stable - I won't tread on your toes if you won't tread on mine".
} 


\section{resenhas}

Ana Carolina Warigoda Guedes, Filipe Starke Lee, Celso Akihide Shiroma, Erica

Fernandes Costa, Mateus Trigo Gonçalves

Guerra Mundial. Dessa forma, é possível dizer que o autor defende uma identidade okinawana, em detrimento de uma assimilação japonesa; mas não se pode ir tão longe quanto afirmar que ele ainda defende a presença estadunidense no arquipélago.

Por fim, vale concluir reforçando a importância da obra de Kerr na produção acadêmica em língua inglesa sobre a História de Okinawa, e seus esforços - ainda na metade do século XX - por construir uma história crítica e fundar questões para estudos posteriores.

\section{Referências Bibliográficas}

DEUTSCHEN NATIONALBIBLIOTHEK. Katalog der Deutschen Nationalbibliothek. Catálogo da biblioteca nacional alemã. Disponível em: <http://d-nb.info/gnd/173129765>. Acesso em: 13 dez. 2018.

HOOVER INSTITUTION ARCHIVES. Register of the George H. Kerr papers. Online Archive of California, 2003. Disponível em: <http://www.oac.cdlib.org/findaid/ark:/13030/kt558013kc/>. Acesso em: 13 dez. 2018.

JENKINS, A. P. "G.H. Kerr's Okinawa: The History of an Island People and Beyond" The Ryukyuanist: a newsletter on Ryukyuan/Okinawan Studies, Urbana and Champaign, $\mathrm{n}^{\circ}$ 52, Verão/2001. Disponível em: <http://www.uchinanchu.org/uchinanchu/ryukyuanist.htm>. Acesso em: 13 dez. 2018.

KERR, George H. OKINAWA: The History of an Island People. Revised edition. Tokyo, Turtle Publishing, 2000[1958] 